Chronic Obstructive Pulmonary Diseases:

Journal of the COPD Foundation

COPD

\author{
Editorial
}

\title{
Fifty Years of the Division of Lung Diseases and the Evolution of Pulmonary Research and Medicine
}

\author{
James D. Crapo, $\mathrm{MD}^{1,2}$
}

\begin{abstract}
Abbreviations: National Heart, Lung, and Blood Institute, NHLBI; chronic obstructive pulmonary disease, COPD; Genetic Epidemiology of COPD; COPDGene ${ }^{\circledR}$

Citation: Crapo JD. Editorial: fifty years of the Division of Lung Diseases and the evolution of pulmonary research and medicine. Chronic Obstr Pulm Dis. 2019;6(4):292-296. doi: https://doi.org/10.15326/jcopdf.6.4.2019.0160
\end{abstract}

1 Editor in Chief, Chronic Obstructive Pulmonary Diseases: Journal
of the COPD Foundation

2 National Jewish Health, Denver, Colorado

\section{Address correspondence to:}

James D. Crapo, MD

Email: crapoj@njhealth.org

\section{Keywords:}

National Heart, Lung and Blood Institute; NHLBI; Division of Lung Diseases; DLD; chronic obstructive pulmonary disease; COPD; pulmonary research; pulmonary training; history of pulmonary research

Note: $A$ version of this editorial was presented as a "historical perspective" speech at the National Heart, Lung, and Blood Institute's Division of Lung Diseases Symposium, " 50 Years of Progress in Pulmonary Science" in April 2019 at the National Library of Medicine in Bethesda, Maryland.

\section{Introduction}

In 1969, Neil Armstrong made one giant leap for mankind, 350,000 fans descended on farmland in Woodstock, New York, the Beatles performed their last live performance and the National Heart Institute changed pulmonary medicine and research forever when it expanded to become the "National Heart and Lung Institute." Shortly after, Claude Lenfant, MD, accepted the position of Director of the Pulmonary Office, which would later become known as the Division of Lung Diseases.

This momentous occasion occurred during my 3rd year of medical school and it was an exciting time to be starting in medicine. Throughout the century before, lung disease was the king of disease-it was the most common cause of hospitalization. But by the 1960s it was believed that this had been conquered. Tuberculosis, the "white plaque" was finally under control and hospital beds for lung disease were being closed all over the country. At the same time other exciting developments were occurring in the pulmonary world-surfactant was discovered, electron microscopy was becoming common, allowing us to look at molecular and cellular levels. Ewald Weibel published his book "Morphometry of the Human Lung" which expanded our knowledge of lung anatomy and the bronchoscope came to America. These breakthroughs helped transform pulmonary medicine.

Unfortunately, a new trend was also on the risepublic health officials noticed a new increase in chronic obstructive lung disease. (See Figure 1). With this realization, the then Secretary of Health, Education and Welfare, Robert Finch, called for the creation of the Office of Pulmonary Research...and the rest, as they say, is history.

\section{The Early Days of Research}

My first experience as an investigator with the Division of Lung Diseases was in the early 1970s and involved the use of extracorporeal membrane oxygenation (ECMO) for acute respiratory distress syndrome (ARDS). I was a junior faculty member at Duke University and joined the pathology center for the ECMO project lead by Phil 
Figure 1. Time Course of Pulmonary Mortality

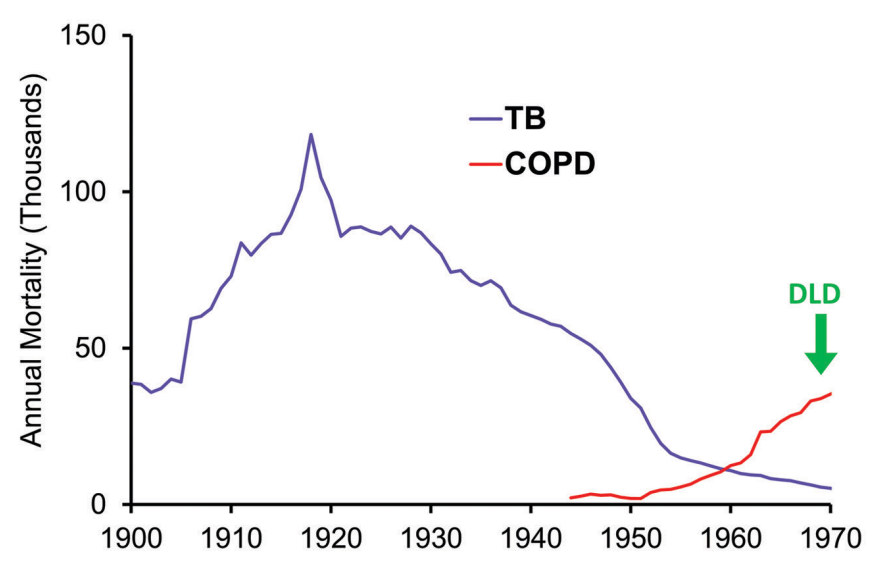

Mortality data from CDC

Figure provided by the Division of Lung Diseases, National Heart, Lung, and Blood Institute, 2019.

Pratt, MD, to review these cases. The results were not good-90\% of the patients died-but the Division of Lung Diseases did not give up on optimizing therapy for acute lung injury and over the next few decades the Division would support research in multiple areas that ultimately impacted on how severe, acute lung injury is treated. (See Figure 2). With this continued focus, through the 1990s and into the early 2000s mortality for ARDS dropped significantly and today averages around $20 \%$.

\section{An Emphasis on Training}

While these many research projects on ARDS were being conducted within the Division, parallel research programs focused on training were implemented. The goal was to expand the pool of researchers dedicated to respiratory research. In the words of the Division of Lung Diseases' current Director, James P. Kiley, PhD, "The initial programs sought to train researchers who would return to their home institutions to train more researchers. A sort of 'go forth and multiply approach.'”

This constant emphasis on training adapted through the years from an early focus on lung physiology to a focus on basic science and then to a focus on translational (basic science to clinical) research in the 1990s. The Division encouraged clinical trials that would translate previous findings into patient management in the 1990s and early 2000s. Today a new focus on training in the "omics" (genomics, proteomics, metabolomics, epigenomics) encourages an emphasis on novel and personalized treatments.

A commitment to training through the past 5 decades reflects the Lung Division's open and creative leadership with a primary focus on trainees and on programs that will stimulate them. Having served

\section{Figure 2. Advances in Acute Respiratory Distress Syndrome Research}

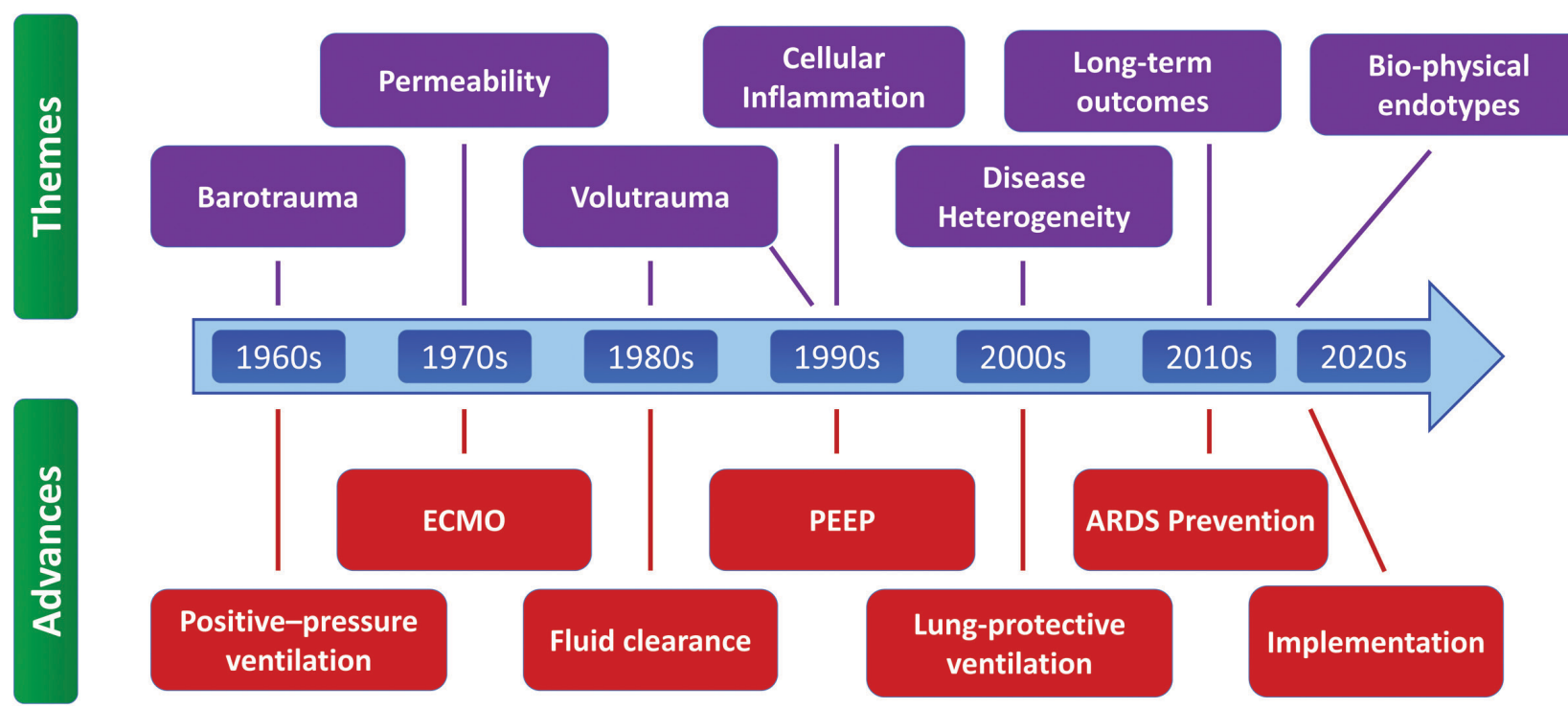

Figure provided by the Division of Lung Diseases, National Heart, Lung, and Blood Institute, 2019 
in positions on the Division's Pulmonary Diseases Advisory Committee and its Board of External Experts, I know that questions like, "how do we create a program?" "what is needed in the field?" "what can we do to stimulate it?" and "where is the optimal opportunity to grow this?" are always asked.

The Division's budget for training has expanded from $\$ 5$ million/year when the Division launched to today's current budget of $\$ 690$ million. This tremendous growth reflects the Division's commitment to create a vibrant pulmonary research community through strong, continuous training programs.

\section{An Ongoing Problem: COPD}

Unfortunately, the disease that drove the creation of the Division of Lung Diseases, has persisted throughout the Division's history and remains a challenge today-50 years after it was identified as a growing problem. Tackling chronic obstructive pulmonary disease (COPD) and its increasing mortality has been perhaps the Division's greatest battle, and one that has shaped the course of pulmonary research.

Over the 50 years of its history, the National Heart, Lung, and Blood Institute's (NHLBI) Division of Lung Diseases has funded countless studies to better understand COPD, to attempt to stop its everincreasing mortality and to ultimately bend the curve down, towards prevention. (See Figure 3).
The Genetic Epidemiology of COPD (COPDGene ${ }^{\circledast}$ ) study, funded by the NHLBI in 2007, is one of the largest and longest studies devoted to better understanding this persistent, heterogeneous disease by examining underlying genetic factors. The COPDGene ${ }^{\circledR}$ cohort includes more than 10,000 individuals from across 21 medicals centers who have now been followed for up to 12 years. Close to 40,000 chest computed tomography scans have been taken in addition to collecting clinical histories, lung physiologic data and blood samples for assessment of omics. COPD is now a major player in the exciting new era of big data (See Figure 4).

With the support of the NHLBI and the Division of Lung Diseases and hundreds of investigators world-wide there have been over 320 COPDGene ${ }^{\circledR}$ papers sharing results, analysis and conclusions. Today we are poised to propose a major change in the diagnosis of COPD that will put the field on the pathway to prevention- and change the future of this disease. (Editor's note: A Special Issue of the JCOPDF containing the COPDGene's groundbreaking research and 2019 proposal to "redefine COPD diagnosis guidelines" will be launched in November 2019).

In addition to supporting COPDGene ${ }^{\circledR}$ and many other COPD-related research studies, the Division also understands the importance of addressing patients' daily needs. With this as their primary focus, the Division created the comprehensive COPD National Action Plan after seeking input from a large group of stakeholders including patients and their families,

\section{Figure 3. Pulmonary Disease Remains a Challenge}

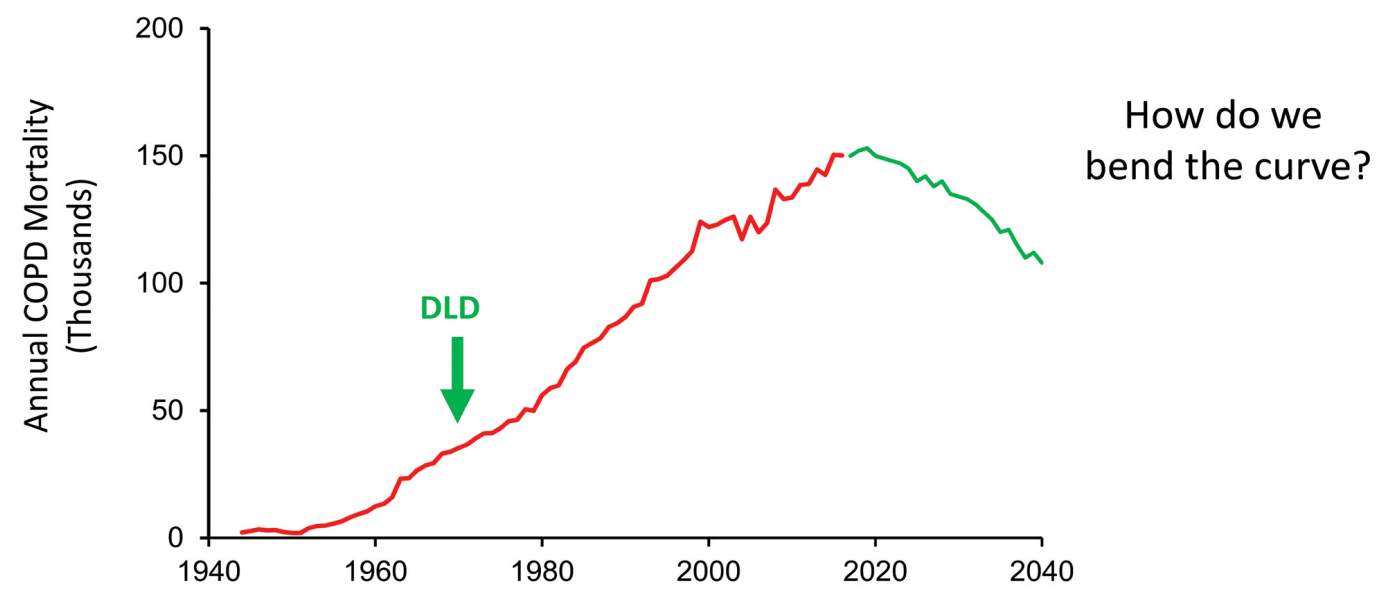

Figure provided by the Division of Lung Diseases, National Heart, Lung, and Blood Institute, 2019 . 


\section{Figure 4. The Future-Big Data}

\section{Genetic and Omic Findings}

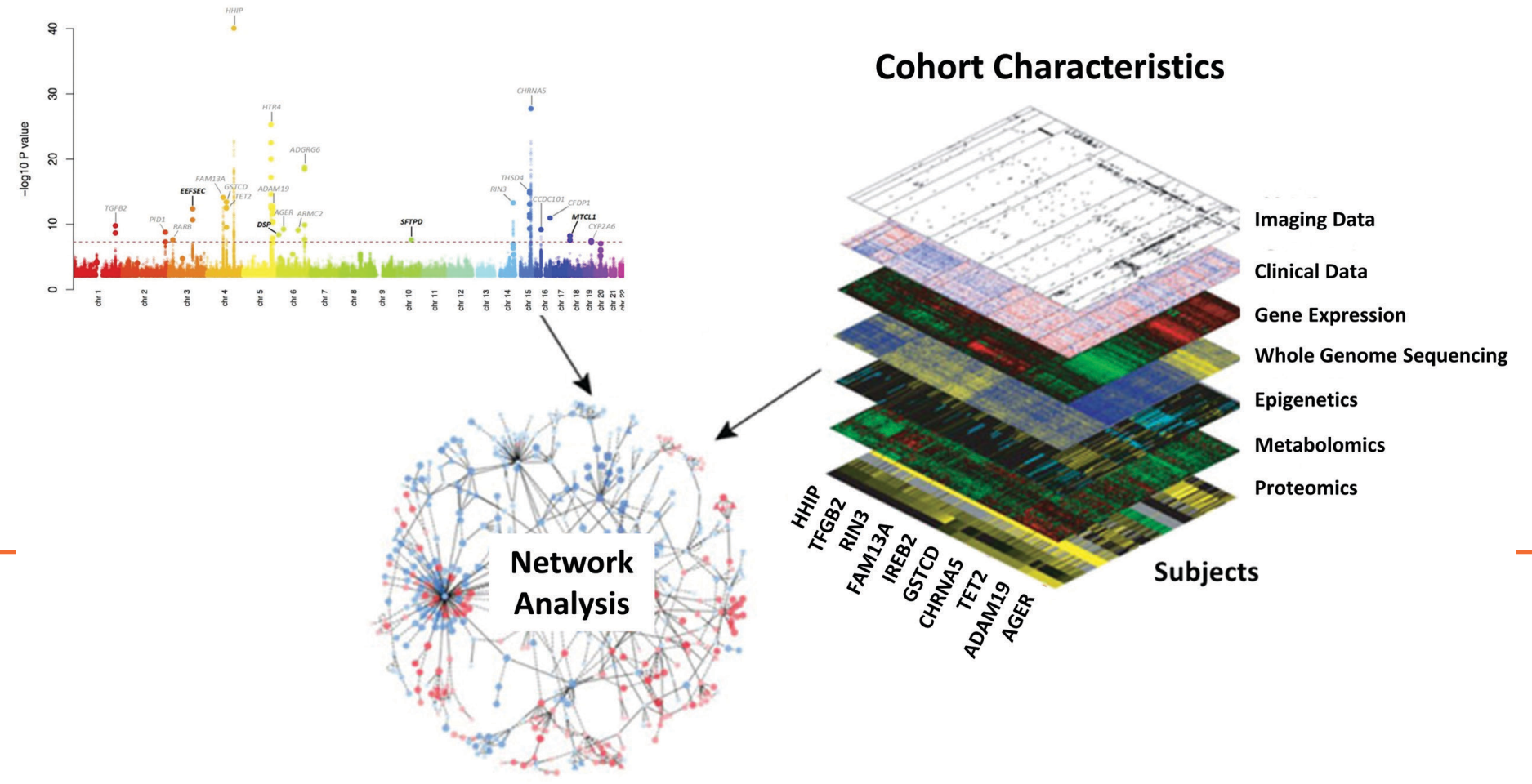

Figure provided by the Division of Lung Diseases, National Heart, Lung, and Blood Institute, 2019.

government agencies, professional societies, industry partners, physicians and public interest groups.

\section{The Future}

A $s$ we pause this year to honor the Division on its 50th anniversary, it is appropriate to also look to the future and the next 50 years. Following an extensive "strategic visioning" process that gathered input from 4000 stakeholders in all 50 states and 42 countries around the world, the NHLBI and its Division of Lung Diseases have created a vision for the future that includes the development of personalized medicine, exploring regeneration opportunities for the lung and optimizing public health approaches to prevent lung disease. (See Figure 5).

\section{And Finally}

As part of our celebration of the Division's 50th anniversary, the JCOPDF is pleased to include in this issue 2 comprehensive reviews which describe the significant progress made in the last 50 years in pulmonary medicine and research. David Mannino, MD, provides a look at NHLBI-sponsored studies which have enabled progress in understanding the epidemiology of COPD and Robert Wise, MD, and Jerry Krishnan, MD, provide a review of landmark clinical trials supported by the NHLBI that had a significant impact on our understanding of COPD and how best to treat it. 


\section{Figure 5. Strategic Vision for the Future}
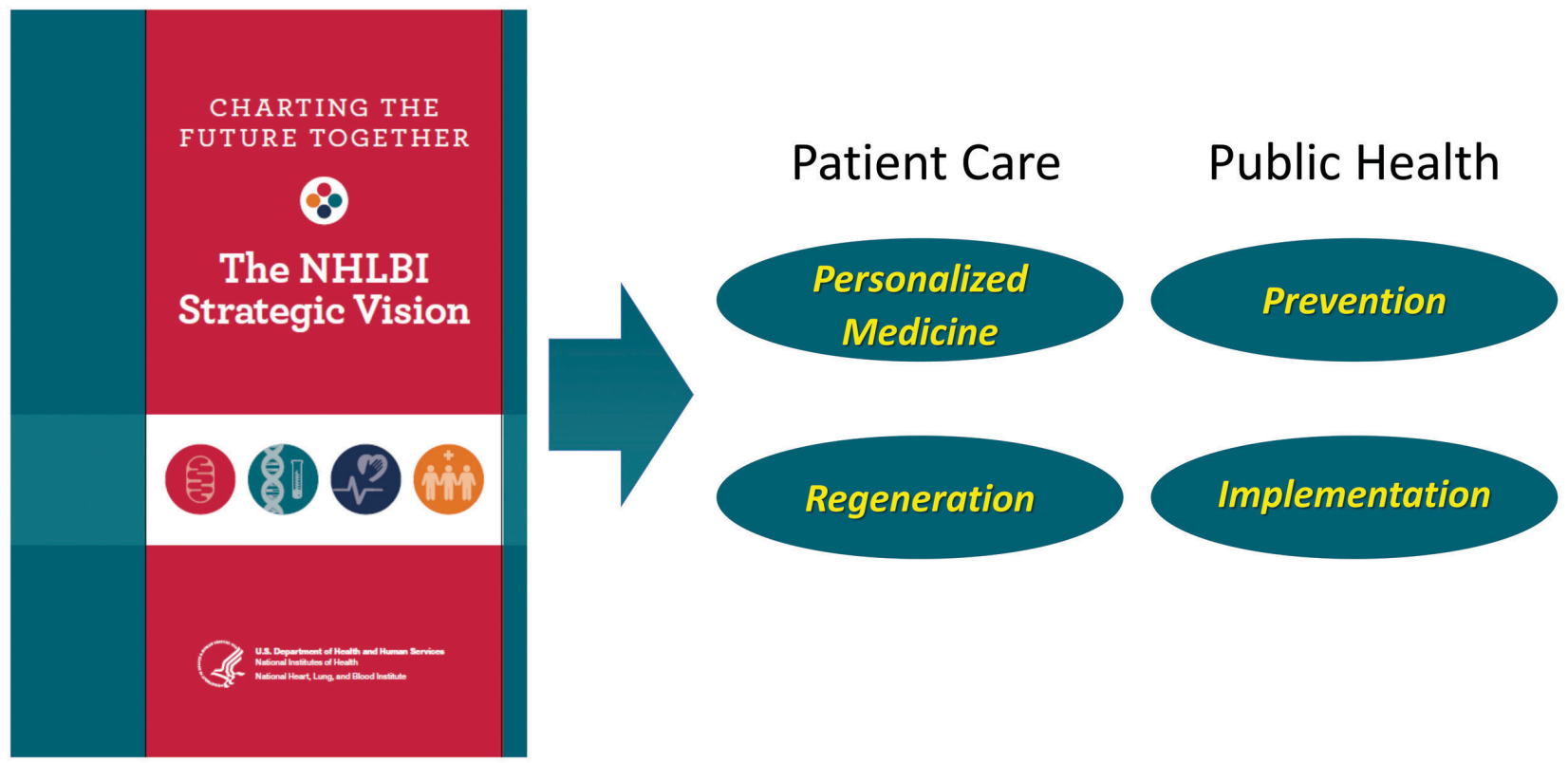

Figure provided by the Division of Lung Diseases, National Heart, Lung, and Blood Institute, 2019 . 